\title{
How Society Shapes Language: Personal Pronouns in the Greater Burma Zone
}

\author{
Müller, André ; Weymuth, Rachel
}

\begin{abstract}
In the "Greater Burma Zone", an area that includes Myanmar and adjacent regions of the neighboring countries, there are two different systems of personal pronouns that occur predominantly: a grammatical one and one that we call "hierarchical system". The aim of this paper is to explain the two systems and their development. A sample of 42 languages shows that smaller language communities have grammatical systems and the most dominant languages today have hierarchical ones. Besides these two groups, there are also some languages with a "mixed system", which means the grammatical system is retained and only a few honorific terms are added as pronouns. An important question will therefore be why the systems are distributed just in this way. Several factors seem to play a role, among them sociocultural structures, historical developments and language contact.
\end{abstract}

DOI: https://doi.org/10.1515/asia-2016-0021

Posted at the Zurich Open Repository and Archive, University of Zurich ZORA URL: https://doi.org/10.5167/uzh-141158

Journal Article

Published Version

Originally published at:

Müller, André; Weymuth, Rachel (2017). How Society Shapes Language: Personal Pronouns in the Greater Burma Zone. Asiatische Studien / Études Asiatiques, 71(1):409-432.

DOI: https://doi.org/10.1515/asia-2016-0021 


\title{
André Müller* and Rachel Weymuth How Society Shapes Language: Personal Pronouns in the Greater Burma Zone
}

DOI 10.1515/asia-2016-0021

\begin{abstract}
In the "Greater Burma Zone", an area that includes Myanmar and adjacent regions of the neighboring countries, there are two different systems of personal pronouns that occur predominantly: a grammatical one and one that we call "hierarchical system". The aim of this paper is to explain the two systems and their development. A sample of 42 languages shows that smaller language communities have grammatical systems and the most dominant languages today have hierarchical ones. Besides these two groups, there are also some languages with a "mixed system", which means the grammatical system is retained and only a few honorific terms are added as pronouns. An important question will therefore be why the systems are distributed just in this way. Several factors seem to play a role, among them sociocultural structures, historical developments and language contact.
\end{abstract}

Keywords: Myanmar, linguistics, pronouns, sociocultural structures, historical development

\section{Introduction}

In the Greater Burma Zone, a region encompassing modern Myanmar and bordering areas within China, India, Bangladesh, Laos, and Thailand, over a hundred languages are spoken that mainly belong to the Sino-Tibetan, TaiKadai, and Austroasiatic language families. The systems of personal pronouns used in these languages can be classified into two main types, which behave like extrema on a continuum. There are the so-called "grammatical systems", a closed class with up to a dozen pronouns marked for various grammatical categories. The other type are the so-called "hierarchical systems", an open class of pronouns, often grammatically underspecified, but highly marked for

\footnotetext{
*Corresponding author: André Müller, Department of Comparative Linguistics, University of Zurich, Plattenstrasse 54, 8032 Zurich, Switzerland. E-mail: andre.mueller3@uzh.ch Rachel Weymuth, Department of Comparative Linguistics, University of Zurich, Plattenstrasse 54, 8032 Zurich, Switzerland. E-mail: rachel.weymuth@uzh.ch
} 
the complex relation between speaker and addressee according to their relative position in the society. The latter group mainly comprises of large lowland languages, like Burmese (and in other countries of mainland Southeast Asia also Thai, Lao, Khmer, and Vietnamese). Grammatical pronoun systems are usually found in smaller, peripheral languages such as Palaung, Jinghpaw or the Karenic languages. Furthermore, there are languages geographically "inbetween", spoken on the plateaus of the Greater Burma Zone, that have mixed pronominal systems showing features of both grammatical and hierarchical systems.

Based on a database developed in the project The Greater Burma Zone - A Transitional Zone of Languages and Peoples, the present study shows the geographic distribution of these pronominal systems in and around Myanmar. Geography probably indirectly influences the shape of the languages, in which the mediating factor is mainly the economy (favorable wet-rice agriculture in the lowlands vs. less surplus from dry-rice farming in the highlands), effecting the political powers of the societies in these areas. This, in turn, directly influences the type of society found among these peoples: lowland societies tend to be strongly hierarchically structured, whereas highland societies have more egalitarian societal systems. Throughout the time, this difference manifests itself in hierarchical pronominal systems among lowland languages, while the languages of the egalitarian societies maintained their original grammatical systems reconstructable for all three language families.

The factors leading to these systems and their distribution in Myanmar and beyond will be the main point discussed in this paper. Apart from the insight into the languages of the area, this study presents an example of how linguistic phenomena can be explained historically and sociologically.

\section{The languages of the Greater Burma Zone}

The latest version of the Ethnologue lists 117 living languages in Myanmar today, ranging from the official state language Burmese, spoken by about 32 million L1 speakers and 10 million L2 speakers, to languages with only a few hundred speakers. ${ }^{1}$ The "borders" of these speech communities hardly coincide with modern political borders, and many of the languages are not only spoken in the Republic of the Union of Myanmar, but also in neighboring countries. It thus makes sense to look at the language situation in a broader area that includes

1 Lewis et al. 2016. 
adjacent regions, especially in Thailand, India and China. Therefore the term Greater Burma Zone (GBZ) is more suitable.

Most of the languages spoken in the GBZ can be classified into three major language families: Sino-Tibetan is the biggest family in the area, with members spoken all over Myanmar and China, as well as in adjacent regions of India. Within Myanmar they include Burmese, Jinghpaw, Karen, Pa'o, Lisu, the various Chin and Naga varieties, and others. Tai-Kadai languages in Myanmar are mainly Shan and its two close relatives Khamti and Khün. Outside of Myanmar several Tai languages are spoken in southern China, Laos, Thailand and some in Assam. Thai and Lao are also members of this family and are official state languages in Thailand and Laos, respectively. The third family is Austroasiatic, with official state languages in Cambodia (Khmer) and Vietnam (Vietnamese). Within Myanmar the languages Mon, Wa, Danau, the Palaung varieties, and others belong to this family. In addition, there are also IndoEuropean, Hmong-Mien and Austronesian languages spoken in the GBZ.

Map 1 shows the rough distribution of the major speech communities discussed in this article.

\section{Personal pronouns}

One grammatical domain in which influence from the types of social systems is evident are personal pronouns. Personal pronouns are a subset of pronouns, used to refer to speech act participants, that is, the speaker and the addressee. ${ }^{2}$ In this paper, also third person pronouns are included, although strictly speaking they are not speech act participants and thus are often not considered personal pronouns. Dixon describes personal pronouns as "shifters". 3 A shifter is a kind of referential index whose "reference shifts regularly, depending on the factors of the speech situation" and whose referential value "depends on the presupposition of its pragmatic value". ${ }^{4}$ Prototypical examples of shifters are tense markers and deixis, the latter of which includes pronominal reference. The nature of the speech event (e. g.: who is talking to whom) thus determines the reference and thereby the correct interpretation of terms like 'I' and 'you' in the discourse.

2 For further discussions on pronouns in general, see Bhat 2004: 132ff; Simon/Wiese 2002; Cysouw 2003.

3 Dixon 2010a: 114, referring to Silverstein 1976.

4 Silverstein 1976: 24. 


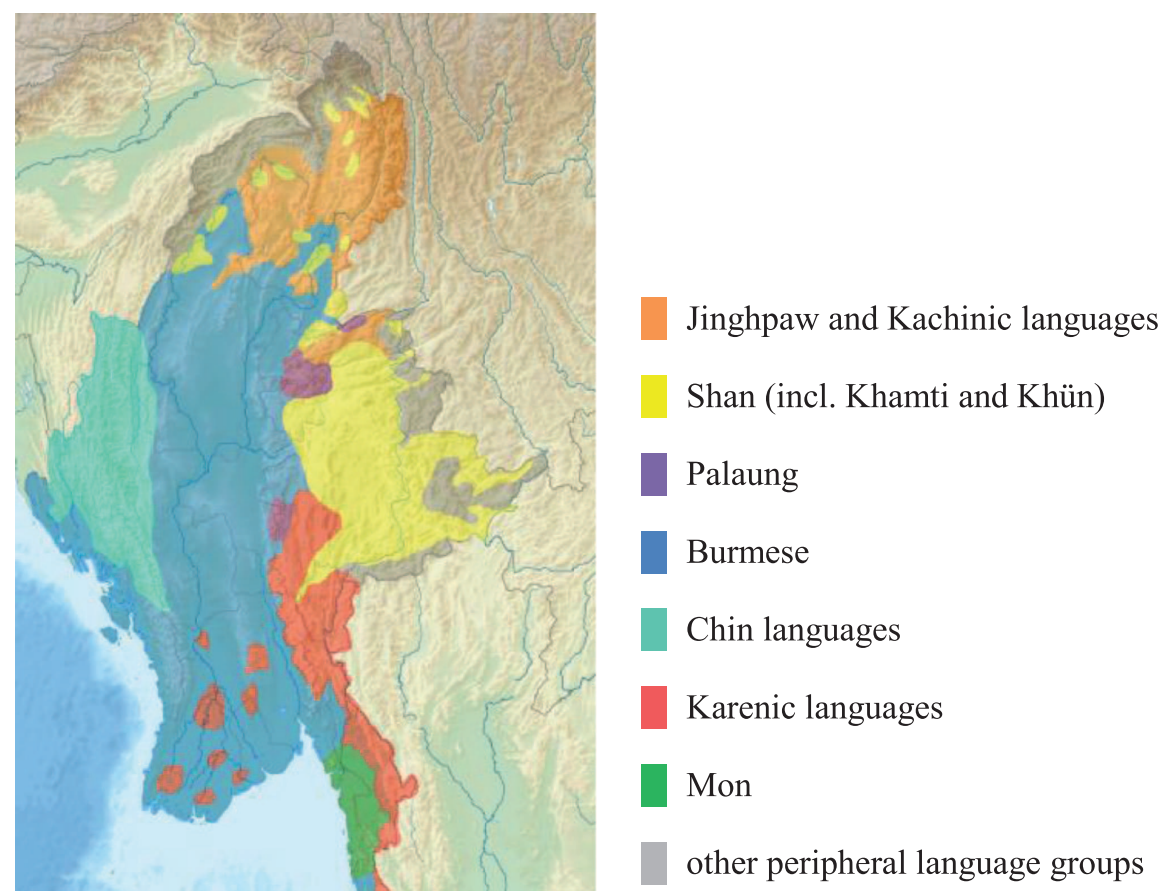

Map 1: Distribution of languages in Myanmar.

Source: Adapted from Huffman 2011.

The assumption in this paper is that in the case of Southeast Asia, the type of pronominal system can be explained by socio-historic trends that have manifested in the languages over time. Personal pronouns are used to refer directly to oneself and the person spoken to, thus they are prone to modification to encode social status, gender, relative age, and other information about the speech act participants that are relevant to being perceived as respectful and 
not losing face. Silverstein speaks of a "deference index" which can encode inequality of social status between speech act participants. ${ }^{5}$ A wide-spread strategy of changing the deference in pronouns is a switch in person or number categories, called "pragmatic metaphors" by Silverstein. This strategy is known from many European languages in which third person and/or plural pronouns are used for polite address of semantically second person singular pronouns (cf. the famous $\mathrm{T} / \mathrm{V}$ distinction in many languages of Europe ${ }^{6}$ ). Some languages of Southeast Asia and partly of East Asia on the other hand have large systems that encode politeness in a much more complex way, involving a potentially infinite number of pronouns. Social factors play a large role in these "hierarchical systems" and set them apart from those pronominal systems that make (almost) exclusively grammatical distinctions, here called "grammatical systems". The next two subsections will describe these two systems in more detail, while Section 3.3 is dedicated to mixed systems and where they are located on the grammatical-hierarchical continuum. Section 3.4 then will deal with the debate on the status of pronouns in hierarchical systems, and the question whether they should be counted as nouns or form a category on their own.

\subsection{Grammatical systems}

The term "grammatical system" here applies to a system in which the core set of personal pronouns in a language forms a paradigm with a small number (usually around 6-9 forms, but smaller and larger sets exist) of personal pronouns. Grammatical pronoun systems mark different grammatical categories, depending on the language in question. By far the most common, almost ubiquitous, distinctions are in person and number. Clusivity is another frequently marked category, distinguished only in the first person non-singular. ${ }^{7}$ Other categories that are less relevant for the languages of the GBZ are animacy and gender; they occur only rarely in the languages of this area. A more common tendency is that third person pronouns can only refer to living beings, while for inanimate objects other strategies of reference are applied (e.g. the use of demonstrative pronouns).

5 Silverstein 1976: 31.

6 Described for instance by Brown/Levinson 1987.

7 An "inclusive we" is the term for a pronoun referring to the speaker, the addresse and potentially others, while an "exclusive we" excludes the addresse. 
Generally such pronoun systems form a closed class, so it is rare for the paradigm to acquire new lexemes through borrowing from another language ${ }^{8}$ or reanalysis of a word from a different part of speech. Languages with a grammatical system often use kinship terms like 'uncle' or 'older sister', professional titles such as 'teacher', or even (nick)names for addressing the speaker or the addressee. Since these are not shifters according to Silverstein's definition, and because they occur in both systems found in Southeast Asian languages, they do not form a distinctive feature and are thus not part of what defines a grammatical system in the scope of this paper.

A typical example of a grammatical system in the GBZ comes from Rumai, a Palaungic language from the Austroasiatic stock, spoken by 140,600 speakers in northern Shan state and parts of Yunnan, China (Table 1). ${ }^{9}$

Table 1: Pronominal system of Rumai Palaung.

\begin{tabular}{|c|c|c|c|c|}
\hline & & SG & DU & PL \\
\hline \multirow[t]{2}{*}{1} & INCL & \multirow{2}{*}{ Pêw } & Pâj & PE \\
\hline & EXCL & & jâj & $j e ̂$ \\
\hline 2 & & mầj & pâj & $p \varepsilon$ \\
\hline 3 & & Pắn & kâj & $k \varepsilon$ \\
\hline
\end{tabular}

Source: Yai Sein 2011.

\subsection{Hierarchical systems}

In contrast to grammatical systems, hierarchical pronoun systems form an open class, ${ }^{10}$ which means that the set of pronouns can easily be enlarged by loanwords or lexical material used for other purposes in the language (e.g. nouns and nominal phrases). The typical hierarchical system forces the speaker to make the choice between a large number of pronouns. These kinds of pronouns tend to carry few grammatical features - indeed they are often underspecified for number and even person - but rather mark social status. ${ }^{11}$ In this way they

8 Although infrequently, this does happen. English they was borrowed from Old Norse peir in the thirteenth century, and the Amazonian language Pirahã has famously borrowed all its pronouns from a neighboring Tupian language: Thomason/Everett 2001.

9 Lewis et al. 2016.

10 Dixon 2010b: 189, 202 describes pronouns as a closed class, though, which would exclude hierarchical systems. Indeed, many linguists treat the 'pronouns' found in languages like Thai, Khmer or Japanese as nouns. See also chapter 3.4 for a discussion of their part of speech status. 11 Cf. Gething 1986 for Thai. 
encode pragmatic usage, rather than formal categories. ${ }^{12}$ According to Silverstein, pronouns in hierarchical systems are composed of a descriptive part marking grammatical features, and a non-referential value marking speaker-addressee relation. ${ }^{13}$ Most of these pronouns are in fact derived from common nouns, and their origins are still more or less transparent. Often, first person pronouns can be traced back to words meaning 'servant' or 'slave', thus humbling the speaker's own social status, while second person pronouns commonly go back to 'master' or 'lord' as a way of elevating or emphasizing the addressee's social status. ${ }^{14}$ Violations of these social rules, intentionally or not, result in various pragmatic effects, such as irony or humor, arrogance, and even insults. ${ }^{15}$

Cooke describes the hierarchical pronoun systems of Thai, Burmese, and Vietnamese in detail and determines various factors playing a role in the choice of pronouns in those languages. ${ }^{16}$ Among them are the gender of the speech act participants, their respective ages, their social status relative to each other, whether the speaker's attitude or the situation is intimate or formal, whether it is restrained or not. As mentioned above, typical of such systems is the underspecification of pronouns for person or number, so for instance Burmese dó used for first person singular and plural, or Thai $k^{h} \breve{a} w$ can be used for both first and third person, and raw can be first or second person.

For the purpose of this analysis, hierarchical systems are thus defined as pronominal systems with an open class of personal pronouns that are not merely defined by grammatical features but take into account the relative social status of the speech act participants. The former nouns used in these systems have become shifters, unlike kinship terms or true titles, and can shift their role according to the speech act participant using it, for example 'slave' being consistently used for the first person, and 'master' for the second person by both participants.

Table 2 gives an incomplete account of the richness of pronominal forms found in modern Burmese, along with a brief explanation of their use and etymological origin in Old Burmese:

Burmese pronouns thus differ in person, formality, politeness, register, social status, monkhood, speaker or addressee's gender. The pronouns inherited

12 Cf. Panagiotidis 2002: 184.

13 Silverstein 1976: $36 \mathrm{f}$.

14 Cf. also Heine/Song 2010: 125.

15 Silverstein 1976: 34f; see also Jenny/Hnin Tun 2016: 60 for Burmese.

16 Cooke 1968. 
Table 2: Pronominal system of modern Burmese.

\begin{tabular}{|c|c|c|c|}
\hline Person & Pronoun & Usage & Origin \\
\hline \multirow[t]{9}{*}{1} & t6anว & polite, male speaker & kywan-tow 'royal slave’ \\
\hline & t6amá & polite, female speaker & kywan-ma 'female slave' \\
\hline & tganou? & formal & kywan-nup 'tiny slave' \\
\hline & $\eta a$ & intimate, rude & original pronoun $(\dot{n} \bar{a})$ \\
\hline & t6ou? & informal, rural, older speaker & contraction of t6anou? \\
\hline & dó & informal, intimate & -tuip $=$ plural suffix \\
\hline & ko & informal, colloquial, same age & kuiy 'body' \\
\hline & $d a b j \bar{\varepsilon}-d \supset$ & speaking to monks & tapañ?-tow 'royal disciple' \\
\hline & $d a b j \bar{\varepsilon}-d \supset-m a ́$ & speaking to monks, female spk. & see above +-ma 'female' \\
\hline \multirow[t]{8}{*}{2} & $k^{h} a m j a ̀$ & polite, male speaker & khan̉ bhurāḥ 'dear Lord' \\
\hline & $\sin$ & polite, female speaker & hran் 'master' \\
\hline & $\operatorname{nin}$ & intimate, female spk./addressee & original pronoun (nai்) \\
\hline & $\min$ & intimate, male spk./addressee & maǹh 'king' \\
\hline & jì & informal, female referent & (uncertain) \\
\hline & to & informal, female speaker & to 'royal suffix' \\
\hline & $\theta$ in & formal & san் 'monk, august person' \\
\hline & lu-ç্টি-min & formal & lū-krīḥ-marị̣ 'person-big-king' \\
\hline \multirow[t]{3}{*}{3} & $\theta u$ & usually animate & sū 'person' \\
\hline & $\theta u-m a ́$ & female referent (written style) & $s \overline{\text { - }} m a$ 'female person' \\
\hline & din/dìn & derogatory, angry & (uncertain) \\
\hline
\end{tabular}

Source: Compiled after Cooke 1968; Bradley 1993; Jenny/Hnin Tun 2016.

from Old Burmese are now used merely in intimate situations and are considered rude when used with people of higher status.

\subsection{Mixed systems}

In mixed systems, grammatical personal pronouns are used, and nouns like 'master' and 'servant' are added to them for respect. The existence of such mixed pronominal systems shows that the types of the personal pronoun systems are not disjunct, but probably rather points on a scale ranging from completely grammatical to entirely hierarchical.

\subsubsection{Shan}

Shan, the second-largest language in Burma with around 3 million speakers, is spoken in the highland plateau of the Shan State and in different pockets in the 
Kachin State and the Sagaing Region further to the northwest. Shan's grammatical personal pronoun system consists of nine pronouns (Table 3):

Table 3: Shan grammatical personal pronominal system.

\begin{tabular}{llll}
\hline & SG & DU & PL \\
\hline 1 & kěw & $h a ́$ & $h e ́ w$ \\
2 & méw & $k^{h} \check{\gamma}$ & sǔ \\
3 & mén & $k^{h}$ & $k^{h} \check{a} w$ \\
\hline
\end{tabular}

Source: Moeng 1995.

Cushing did not mention the dual pronouns in his grammar. ${ }^{17}$ This might be due to two factors: first, dual pronouns are rarely used, and second, they occur mainly in certain kinds of texts, for example in conversations.

A comparison with Strecker's reconstruction of Proto-Tai displays the loss of the inclusive/exclusive distinction. The first person dual and plural pronouns used in contemporary Shan are cognate with the inclusive forms of Proto-Tai. ${ }^{18}$

Shan also displays the extension of the grammatical pronoun system in the third person dual pronoun $k^{h} \check{a}$, a Southwest Tai development that also occurred in Old Thai.

Cushing mentions the nouns $k^{h} a$ 'servant' and cew 'lord' that are added after the grammatical pronouns for deference, ${ }^{19}$ which means that the honorific compounds in Shan have been in use at least since the nineteenth century, but possibly longer. The same system is still in use today with some more forms like mén cáy 'he' (lit. '3ss male'). ${ }^{20}$

The bare grammatical pronouns are used when superiors address inferiors and among equals in casual conversation. ${ }^{21}$

\subsubsection{Mon}

Mon, an Austroasiatic language of about 743,000 speakers, is spoken mainly in the small area that is now the Mon State, and in some places across the border in

17 Cushing 1887: 34-36.

18 Strecker 1984: 134.

19 Cushing 1887: 34-35.

20 Own data.

21 Cushing 1887: 34-35. 
Table 4: Old Mon (sixth-thirteenth centuries) personal pronouns.

\begin{tabular}{|c|c|c|}
\hline & SG & PL \\
\hline 1 & Pey & poy \\
\hline \multirow[t]{2}{*}{2} & beh & bnah \\
\hline & kum & kum t?eh \\
\hline \multirow[t]{2}{*}{3} & ?ja & Pja t’eh \\
\hline & dẹ & dẹ t?eh \\
\hline
\end{tabular}

Source: Adapted from Jenny/McCormick 2015: 540-541.

Table 5: Personal pronouns in Modern Mon (since seventeenth century).

\begin{tabular}{|c|c|c|}
\hline & SG & PL \\
\hline 1 & ?иа & Poj \\
\hline \multirow[t]{2}{*}{2} & $6 \dot{\varepsilon} ?$ & $6 \bar{\varepsilon} ? t$ \\
\hline & $\begin{array}{l}\text { pèh } \\
\text { manżh }\end{array}$ & $\begin{array}{l}\text { pèh to? } \\
\text { mančh to? }\end{array}$ \\
\hline \multirow[t]{2}{*}{3} & $d \varepsilon h$ & dEh to? \\
\hline & nèh & pèh to \\
\hline
\end{tabular}

Source: Adapted from Jenny 2015: 579.

Thailand. Also the pronominal system of Modern Mon can be classified as mixed, more so than that of Old Mon. Tables 4 and 5 show the pronominal systems of Old and Modern Mon. Although there are some differences between the two systems, the grammatical character of the system is still evident.

Old Mon distinguished three persons and two numbers. However, only in the first and in one of the second person pronouns is number distinguished. The plural of the other pronouns is built by adding the plural marker t?eh to the singular form. In the place of pronouns, honorifics and titles can be used. Among them are tirla 'lord' to show reverence for the second person and the honorific Pey-dik, literally 'I (your) servant'. However, the simple pronoun Pey 'I' is also found in this context. ${ }^{22}$

In Modern Mon, some of the old pronouns have been lost and others have been added. For the second person, the loss concerns kum and the plural form bnah, while in addition to $6 \grave{\varepsilon}$ ? (now derogatory) the two new pronouns pèh (neutral) and manc̀h (only literary language and formal contexts) are in use

22 Jenny/McCormick 2015: 541. 
today. The third person pronoun Pja has been lost and jèh (lit. 'person') that is more polite than $d \varepsilon h$ has been added. Except for the monomorphemic poj '1PL', all the plural forms are built with the plural marker to?. A polite form for the second person which is hardly used in the colloquial language is kala?-?uə 'my lord' or kala?-poj 'our lord'. The noun kala? 'lord' in kala?-?uə 'my lord' or kəla?poj 'our lord' is a polite form for the second person in formal speech. ${ }^{23}$

Mon has not developed a full hierarchical personal pronoun system. Possible reasons for that will be mentioned in Section 5 .

\subsection{Nouns vs. pronouns}

The distinction between nouns and pronouns can be a blurry one when it comes to hierarchical systems. Many of the "pronouns" in modern Thai, Burmese, and partly in modern Mon and Shan, still have homophonous counterparts with full noun phrase status. Bhat shows that it is not at all trivial to define pronouns as a category with fixed borders. He also presents the different points of view that linguists had on the status of hierarchical pronouns (as in Burmese, Thai, or Japanese):

"Some linguists consider these languages as not possessing any pronouns as such, whereas others regard the nominal forms that are used in place of pronouns to be functioning as first or second person pronouns (see Diller 1994). It appears to me that a definite answer to this question can be provided only through an examination of the use of those nouns from the point of view of their ability to denote speech roles as distinct from the individuals who perform those roles." 24

This last point is rather important, because it stretches the fact that the former nouns like 'slave' and 'master' must have lost their literal meaning and can be applied to other individuals as well. And indeed, mainland Southeast Asia is not the only region where one can find hierarchical pronoun systems. Japanese ${ }^{25}$ and Korean ${ }^{26}$ have very similar systems, and so do Javanese, ${ }^{27}$ Balinese $^{28}$ and Acehnese. ${ }^{29}$ Sugamoto analyzed the pronouns of Japanese and concluded that their syntactic and pragmatic characteristics are to be found somewhere inbetween those of explicit noun phrases and prototypical pronouns as found in most other languages.

23 Jenny 2015: 578-579.

24 Bhat 2004: $30 \mathrm{f}$.

25 Kurokawa 1972.

26 Lee/Ramsey 2000: 89-94.

27 Errington 1988.

28 Barber 1977.

29 Durie 1985. 
He speaks of a "pronominality scale" or a "'noun-pronoun continuum". 30 Hinds compares the pronominal systems of Japanese with that of languages like English and finds several points where they differ in structure and function, while still emphasizing the similarity between Japanese pronouns and nouns. In Japanese, pronouns can directly follow demonstrative pronouns, as well as be modified by relative clauses and adjectives. ${ }^{31}$ Nevertheless, he still counts them as pronominal. Panagiotidis argues that in languages such as Japanese and Thai most pronouns differ from prototypical pronouns in that they are not determiners, as they form an open class, are not encoded by unique formal feature such as $[ \pm$ polite] or $[ \pm$ honorific], and can be modified by different kinds of attributes. He shows that such "N-pronouns" also exist to a lesser extent in languages with grammatical pronoun systems (e.g. English one). Panagiotidis' conclusion is that in Japanese and Thai all pronouns are in fact nouns, ${ }^{32}$ headed by a determiner that is not overtly expressed. ${ }^{33}$

Several linguists have noted that nouns are one of several common sources for the grammaticalization process leading to personal pronouns, ${ }^{34}$ so the idea that pronouns can be derived from nouns is not new. The most common subclasses or domains from which nouns are reanalyzed as pronouns are $^{35}$ :

a) honorific expressions used for high-ranking personalities

b) terms for social status distinctions

c) kin terms

d) terms for professions

e) generic nouns for human beings, or based on distinctions of sex and age

Indeed, examples for each of these domains can be found in the hierarchically structured pronoun systems. Additionally, all of the necessary stages of the 'noun-to-pronoun channel', ${ }^{36}$ are evident: the word in question can still be used as a third person referent in other contexts, but it is regularly used in reference to a first or second person as well (extension), they lose their lexical meaning (desemanticization), and they at least partly lose their ability

30 Sugamoto 1989.

31 Hinds 1986: 241ff, cited by Bhat 2004: 31.

32 Several others have already made this argument for Japanese (e. g. Fukui, 1987; Noguchi, 1997).

33 Panagiotidis 2002.

34 E.g. Humboldt 1830; Blake 1934; Cysouw 2003: 13; Siewierska 2004.

35 According to Heine/Song 2010: 121f; 2011: $596 \mathrm{f}$.

36 Heine/Song 2010: 122. 
to take modifiers (decategorialization). ${ }^{37}$ Erosion, i. e. the loss of phonetic substance, can only be shown in a few examples in Burmese, such as t6ou? '1sG' (informal) being a truncation of t6anou? '1sG' (formal), itself stemming from t6un nou? 'menial slave'. However, erosion is not a necessary condition for grammaticalization, and only the other three are central parameters thereof. $^{38}$ Furthermore, an inverse process of degrammaticalization cannot be expected: it is unheard of that a deferential pronoun becomes a full noun such as 'master' or 'servant' again, in a language that had previously lost the nominal meaning of the respective word. ${ }^{39}$

Thus, it makes sense that in the languages with hierarchical systems the words in question are actually treated as pronouns that were derived through grammaticalization processes from nouns. However, titles, kinship terms, and professions (such as 'general', 'uncle', 'teacher', respectively) used as forms of address are common to languages of both systems. They cannot be classified as shifters and are thus not treated as part of the hierarchical systems, in contrast to 'slave' and 'master' which actually shift in reference, i. e. 'slave' for first person and 'master' for second person.

\section{Distribution of the pronominal systems in the GBZ}

Map 2 shows Myanmar and its surrounding with a sample of 42 languages overlayed. ${ }^{40}$ The sizes of the dots represent the size of the community on a logarithmic scale, the smallest being languages with less than 50,000 speakers, the biggest dots represent languages with over 10 million speakers, such as Burmese or Thai. The colors indicate the type of their pronominal system, red standing for hierarchical systems, blue for grammatical system, and purple for a mixed system. With the exception of the relatively recently extinct Ahom, the sample only contains living languages in their modern stage and location.

37 In Japanese, Chinese, and Thai, however, both original pronouns as well as derived pronouns can be modified by attributes.

38 Cf. Hopper/Closs Traugott 2003: 133; Heine/Kuteva 2008: 35; Schiering 2010; Heine/Song 2011: $592 \mathrm{f}$.

39 Heine/Song 2011: 618 in their article give even more evidence that the unidirectionality principle holds here.

40 The database for these languages was compiled within the scope of the project from published sources. The authors wish to thank Alys Boote Cooper and Selim Özgür for helping with the compilation. This database is not public, but the data can be provided on request from the authors. 


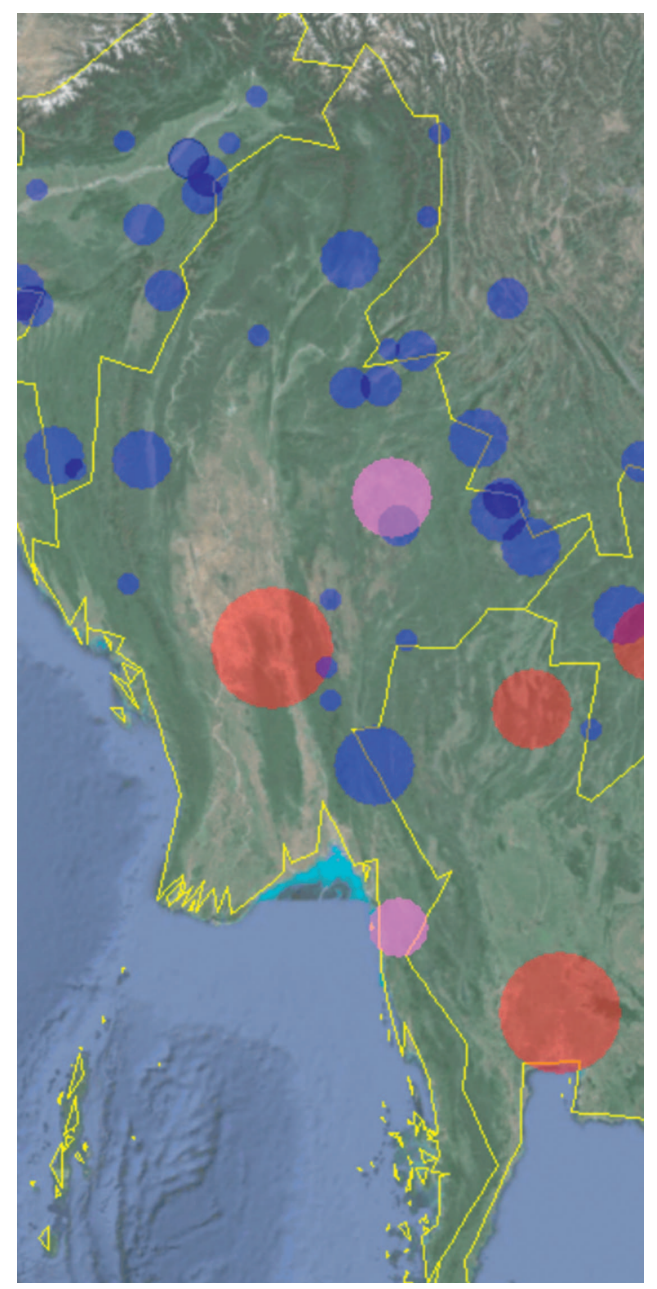

Map 2: Distribution of the pronominal systems.

As the family affiliations of the languages are not encoded in the map, a brief summary is given:

Among the Sino-Tibetan languages shown in the map, only Burmese has a hierarchical system. All other 22 languages in the sample (namely Anong, Apatani, Bawm, Bwe Karen, Chang Naga, Daai Chin, Eastern Kayah, Geba Karen, Jinghpaw, Kadu, Konyak Naga, Lahu, Lashi, Lisu, Lotha, Maru, Mizo, Nocte Naga, Pela, Sgaw Karen, Tangkhul Naga, Zaiwa) have grammatical pronoun systems. There are no mixed ones of this family in the sample. 
Within the Tai-Kadai language family, only the largest languages developed hierarchical pronoun systems: Lao, Northern Thai and Standard Thai are shown on the map as big red circles. Shan has a mixed system. The other 4 languages (Aiton, Phake, Tai Nüa, as well as the now extinct Ahom) have grammatical systems.

Austroasiatic languages with a hierarchical system do not exist in the vicinity of Myanmar, but Khmer and Vietnamese would be counted among them. Mon is classified as having a mixed system, while the 10 others (Blang, Danau, Khasi, Khmu', Mlabri, Pnar, Ruching Palaung, Rumai Palaung, Shwe Palaung, and Wa) all have grammatical pronoun systems.

It is clear from the map that most of the languages with grammatical systems are spoken in highland regions, while all languages with hierarchical systems are found in the lowlands and are large national languages with millions of speakers. The mixed languages fall inbetween those categories in terms of altitude and size. Genetic affiliation does not appear to play a role here. In fact, the pronominal systems of lowland societies have more in common than they have with the systems of their highland "siblings".

\section{Development and maintenance of pronominal systems}

Looking at the examples above, the question about the underlying factors for this disparity of systems and their development arises. Even though the existence and features of such systems have been described by several authors, so far nothing has been published about the origin and development of these systems in general, especially from a socio-historic perspective. It is beyond the scope of this paper to deliver an exhaustive analysis of the factors involved, but some of them will be discussed in the following.

\subsection{Historical development}

The historical, social and economic development of the four language communities whose languages served as examples of the different pronominal systems, namely Mon, Burmese, Shan, and Palaung, will be outlined briefly. They shall be representative for all the other speech communities in Southeast Asia and especially in the GBZ. 
Of these languages, the written sources of Mon from the sixth century $\mathrm{CE}^{41}$ are the oldest. At that time, the Mon occupied the region called Dvāravatī that reached from the Bight of Bangkok across the central plain to the northeast of Thailand. Dvāravatī was not a big coherent kingdom, but there were scattered settlements of which the major ones were moated towns. ${ }^{42}$ The region already had a long trading tradition with the Indian subcontinent and the Mon had adopted political structures and the Buddhist religion with some Hindu elements from there. ${ }^{43}$ Towards the end of the first millennium, Dvāravatī declined due to pressure from the newly arriving Tai from the north and the expansion of the Khmer kingdom of Angkor from the east. ${ }^{44}$ The Mon later settled in the south of Burma and also played a role during the Pagan kingdoms as several Mon inscriptions show, but there was probably never an influential Mon kingdom in Burma. Today, the Mon inhabit roughly the Mon State in Myanmar and a smaller adjacent region in Thailand.

The dominance of the Burmans that lasts until today began with the kingdom of Pagan in the early second millennium. This kingdom spread from Upper Burma over the central plain down to parts of the peninsula. The Burmans practiced Theravāda Buddhism that was adopted from the Mon and/or by direct contact with Sri Lanka. Nevertheless, elements of Hinduism, like the divinity of kings, were also present. ${ }^{45}$

Today, the Shan and the Palaung live in the Shan Hills of Myanmar. The Shan arrived there around the beginning of the second millennium, whereas the Palaung are assumed to be one of the oldest known peoples in the region. ${ }^{46}$ The Shan live in the river valleys, while the Palaung are scattered over the ridges of the hills. This leads to a more hierarchical social structure among the Shan that were organized in small principalities over a long time, while the political power of the Palaung chiefs is restricted to the village level. Both the Shan and the Palaung are Theravāda Buddhists.

Rice culture plays an important role in the prosperity of the people in Southeast Asia. Paddy rice cultivation of the lowlands with their monsoon climate is more productive than the dry-rice and slash-and-burn cultivation of the highlands. Nevertheless, also hill societies like the Palaung in Northern Shan State who extensively cultivate tea have a good income and can

\footnotetext{
41 Jenny 2005: 2.

42 Ricklefs et al. 2010: 26.

43 Glover/Bellwood 2004.

44 Ricklefs et al. 2010: 26.

45 Ricklefs et al. 2010: 47-48.

46 Ricklefs et al. 2010: 11.
} 
produce a surplus. The Palaung are, as already mentioned, Buddhists like the speakers of the other three languages, but many of the other hill peoples are animists or Christians. Scott describes the differences between highland and lowland societies as follows:

\footnotetext{
"The absence of large, permanent, surplus-absorbing religious and political establishments makes for a sociological pyramid in the hills that is rather flat and local when compared with that of valley societies. Distinctions of status and wealth abound in the hills, as in the valleys. The difference is that in the valleys they tend to be supralocal and enduring, while in the hills they are both unstable and geographically confined." 47
}

That means the main source for a very hierarchical society is a large, coherent political entity (kingdom). This is favored by easier accessibility of most parts of the realm, but also by the Indic influence, bringing ideas of political structure, Buddhism and Hinduism to Southeast Asia. The Hindu style of divine kings led to an even steeper hierarchy than Buddhism. The Mon regions have never been a single coherent kingdom, and this may be the explanation why the Mon did not develop a fully hierarchical pronoun system.

\subsection{Rise of the hierarchical pronoun systems}

Before the rise of the first large kingdoms and multinational states, all languages with nowadays hierarchical pronoun systems had grammatical systems. This can be shown for all families. Unfortunately, documents from these times are rare, and due to the nature of these texts, pronouns of the first and second person are even rarer. Often it is necessary to rely on reconstructions and evidence from related languages. In Old Burmese, the pronouns were $\dot{n} \bar{a}$ ' 1 ',

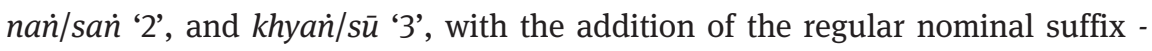
tuiw to mark plural. ${ }^{48} \dot{N} \bar{a}$ and nan must be regarded as "original", as they are the direct reflexes of Proto-Tibeto-Burman ${ }^{*} \eta a$ and ${ }^{*} n a \eta .{ }^{49}$ At this time some honorific non-pronominal forms were used alongside the pronominal addresses, like akyon/akywan '1sG' (lit. 'his servant' ${ }^{50}$ ), atuiwP-kywan '1sG' (lit. 'their servant'), $\dot{n} \bar{a}$-tuiw-kywan '1sG' (lit. 'we servants'), ayain '3sG' (lit. 'that one') and ayan-tuiw

47 Scott 2009: 21 .

48 After Ohno 2005: 272-273.

49 Benedict 1972: 93; Bauman 1975.

50 Ohno 2005: 272 translated akyon/akywan as 'your servant', but an interpretation with the Sino-Tibetan prefix ${ }^{*} a$ - '3sG' is more likely Benedict 1972: 121-123. 
'3PL' (lit. 'those ones'). ${ }^{51}$ The pronominal system of Proto-Tai, the ancestor of both modern Thai and Shan, is reconstructed as a grammatical system involving three numbers, three persons, an inclusive/exclusive distinction and an animate/non-animate distinction in the third person non-singular. ${ }^{52}$ Also for the Austroasiatic languages, out of which Khmer and Vietnamese have hierarchical systems, a grammatical pronoun system is reconstructed. ${ }^{53}$ So what led these languages to develop hierarchical systems over time? Assuming that hierarchical pronoun systems are an areal feature, ${ }^{54}$ they possibly have developed in a few or even a single language and then spread to others. For their development there are essentially two likely chains of events:

Scenario 1: Increased necessity for politeness in speech can lead to an avoidance of pronouns, which in turn can lead to nouns being used instead of pronouns.

Scenario 2: The same necessity for polite speech can lead to augmentation of pronouns with respectful terms such as 'master' and 'slave'. Later, these terms can completely replace the original pronouns in certain situations.

In both scenarios, the main triggering factor is the social hierarchy in the speech community's social system. ${ }^{55}$ The term "social hierarchy" refers to a non-egalitarian layering of the population according to various factors such as birth, age, profession, wealth, achievements, or social status. In a typical hierarchically layered society, one's own position relative to the people one deals with determines the way of behaving towards that person, in particular towards those of higher status than oneself. ${ }^{56}$ Caste systems like the ones in India, Nepal or on Bali are extreme examples of such stratified societies. In Southeast Asia there are no such caste systems, so each individual has at least the possibility of moving up or down the hierarchy, yet is still curtailed in their individual expression. ${ }^{57}$ In such a status-conscious society, "negative politeness" strategies are commonly applied when talking to people of higher or equal status. These strategies include an avoidance of imposition to the addressee leading to a

51 Ohno 2005: 272-273.

52 Strecker 1984: 134.

53 Pinnow 1965; see also Sidwell 2015.

54 Enfield 2005: 185.

55 The idea that macrosociological relationships can be reflected in the grammatical structures of a language is not new, cf. Brown/Gilman 1960 about T/V pronouns in European languages, Dixon 2010a: 17, 20, but also see Silverstein 1988, cited in Agha 1994: 280, who says that it is not possible to get any "social semantic calculus" from the usage of honorific pronouns.

56 This is termed "personhood" by Foley 1997: 266.

57 Foley 1997: 268. 
preference for addressing the person indirectly, using impersonal requests, questions instead of requests, and more. In the first scenario this leads to the avoidance of direct pronominal reference so as not to commit any unwanted face-threatening acts. ${ }^{58} \mathrm{~A}$ strong tendency for pro-drop is indeed a marker of politeness in many languages of the area. ${ }^{59}$ To still be able to refer to the addresse, nominal expressions were then used, emphasizing the different social status of speaker and addressee, which later led to their non-literal application, in which "the speaker understates his or her own social status, describing himself or herself as being of low status while treating the hearer as a personality of high status, deserving a respectful form of address." 60 After the reanalysis of these nouns as pronouns, the original pronouns continued to be used for informal conversations among peers. In the second possible scenario, the required politeness leads to pronouns directly being augmented by the use of nouns like 'master', 'slave', 'your highness', etc. to emphasize the addressee's status and to show - or sometimes exalt - the difference in status between the speech act participants. The pronominal systems of Shan and Mon (see Sections 3.3.1 and 3.3.2) are exemplary of such a development. In the same system, the pronominal parts of the augmented pronouns can then even be omitted, yielding the same hierarchical system as suggested in scenario one.

\subsection{Maintenance of the grammatical pronoun systems}

Smaller hill-dwelling peoples had only very restricted contact to large state languages in the past, this prevented them from receiving enough influence to change their social system and along with it their pronominal system. The paradigmatic complexity seen in the peripheral languages can be related to the community size and the social structures connected to it. While the larger states with their royal court culture developed and urbanization took place, the communities housing the peripheral languages in the hills remained small and intimate, with a few hundred or a thousand individuals. In such communities, the amount of shared knowledge is higher, contact with outsiders is less frequent, and the social network tighter and usually more egalitarian than in large

58 Brown/Levinson 1987.

59 Helmbrecht 2013 lists Burmese, Thai, Khmer, Vietnamese, Indonesian, Korean, and Japanese as examples for the pronoun avoidance strategy. This set is almost identical with the languages having hierarchical systems mentioned in this paper.

60 This is the so-called "asymmetric-role model" proposed by Heine/Song 2011: 607. 
urban societies or whole states. ${ }^{61}$ Due to the mutual acquaintance and the shared generic information, a complex system of deictic expressions is more convenient and economic than overt lexical marking of all referents. These deictic expressions can include pronouns, demonstratives, ${ }^{62}$ as well as complex paradigms of tense or evidentiality. ${ }^{63}$ Furthermore, small scale communities tend towards a conservation of norms, further supported by their low amount of external contact, ${ }^{64}$ while large quantities of L2 speakers can simplify the paradigms considerably through incomplete or imperfect learning. Conservatism as well as the above mentioned trend to paradigmatic complexity should therefore be seen as the intermediate factors between social structure and the grammatical pronoun system in the context of Southeast Asian languages.

\section{Conclusion}

This paper presents evidence that there are two different types of personal pronoun systems in the languages of the GBZ and the rest of Southeast Asia, as well as an intermediate type which is essentially a mixture of both. We discussed the question of whether the open class of personal pronouns in the hierarchical system can really be called "pronouns" and gave reasons to distinguish them from common nouns. This distinction is essential for the rest of the discussion, as it defines the nature of these systems and helps to explore their development. A survey of 42 languages spoken in the GBZ and a look into surrounding languages showed a strong correlation between the type of pronoun system and the kind of society the speakers live in: hierarchical systems are found in large national languages spoken by rather strictly stratified societies in lowland areas, while grammatical systems are found mostly ${ }^{65}$ in the higher altitudes in languages that belong to Scott's Zomia. ${ }^{66}$

As for the explanation of this correlation, a fully accurate account of what led to the development of these systems is not possible, so we attempted to give

61 Cf. Trudgill 2011: 102; Givón 1979: 297; Tadmor 2015.

62 E.g. many of the peripheral languages in the GBZ distinguish between relative altitudes in their demonstrative system.

63 Cf. also Kay 1976; Keenan 1976; Trudgill 2015.

64 Trudgill 2011: 103.

65 Exceptions are some varieties of Karen that are spoken in the lowlands around the Irrawaddy delta.

66 Following Scott 2009. 
plausible explanations for the initial rise of these systems in several languages and a subsequent spread into other languages of the area. Not only social factors play a role, but also historical factors such as the influence from Indic culture during the development of these nations.

A lot more work is needed in this very underresearched area (both in the geographic as well as the academic sense). It will be essential to look at early written texts to show with empirical methods when and how these national languages switched their system, which will also help in determining how the systems were borrowed into neighboring languages. A closer comparison with languages outside of mainland Southeast Asia, like Japanese, Korean, and the Austronesian languages of Malaysia and Indonesia, will surely contribute to a better understanding of this phenomenon. It is our hope that the insight brought forward in this paper demonstrates the importance of this research in both sociolinguistics and local history, and gave new ideas for future research that could someday give us a clearer picture of the ways society can influence language on a larger time-scale.

Funding: Schweizerischer Nationalfonds zur Förderung der Wissenschaftlichen Forschung, (Grant/Award Number: '100012_150136')

\section{Bibliography}

Agha, Asif (1994): “Honorification”. Annual Review of Anthropology 23: 277-302.

Barber, Charles Clyde (1977): A Grammar of the Balinese Language. Aberdeen: Aberdeen University Library.

Bauman, James John (1975): Pronouns and Pronominal Morphology in Tibeto-Burman. PhD Dissertation. Berkeley: University of California.

Benedict, Paul K. (1972): Sino-Tibetan. A Conspectus. Cambridge: Cambridge University Press. Bhat, D. N. S. (2004): Pronouns. A Cross-Linguistic Study. Oxford: Oxford University Press. Blake, Frank Ringgold (1934): "The origin of pronouns of the first and second person". The American Journal of Philology 55: 244-248.

Bradley, David (1993): “Pronouns in Burmese-Lolo". Linguistics of the Tibeto-Burman Area 16.1: 157-215.

Brown, Penelope/Levinson, Stephen C. (1987): Politeness: Some Universals in Language Usage. Cambridge: Cambridge University Press.

Brown, Roger/Gilman, Albert (1960): “The pronouns of power and solidarity”. In: Style in Language. Edited by Thomas A. Sebeok. Cambridge, MA: MIT Press, 253-276.

Cooke, Joseph R. (1968): Pronominal Reference in Thai, Burmese, and Vietnamese. Berkeley/Los Angeles: University of California Press.

Cushing, J. N. (1887): Grammar of the Shan Language. Rangoon: American Baptist Mission Press. 
Cysouw, Michael A. (2003): The Paradigmatic Structure of Person Marking. Oxford: Oxford University Press.

Diller, Anthony (1994). “Thai”. In: Semantic and lexical universals. Edited by Cliff Goddard and Anna Wierzbicka. Amsterdam: Benjamins, 149-170.

Dixon, R. M. W. (2010a): Basic Linguistic Theory. Volume 1: Methodology. Oxford: Oxford University Press.

Dixon, R. M. W. (2010b): Basic Linguistic Theory. Volume 2: Grammatical Topics. Oxford: Oxford University Press.

Durie, Mark (1985): A Grammar of Acehnese on the Basis of a Dialect of North Aceh. Dordrecht/ Cinnaminson: Foris Publications.

Enfield, Nick J. (2005): “Areal Linguistics and Mainland Southeast Asia”. Annual Review of Anthropology 34: 181-206.

Errington, J. Joseph (1988): Structure and Style in Javanese: A Semiotic View of Linguistic Etiquette. Philadelphia: University of Pennsylvania Press.

Foley, William A. (1997): Anthropological Linguistics. An Introduction. Oxford: Blackwell. Fukui, Naoki (1987): The Theory of Projection in Syntax. Stanford: CSLI publications.

Gething, Thomas W. (1986): “The Thai Language as a Map of Thai Culture”. In: Essays in Honor of William J. Gedney. Edited by Robert Bickner, Thomas J. Hudak and Patcharin Pevasantiwong. Ann Arbor: University of Michigan, Michigan Papers on Southeast Asia, Center of South and Southeast Asian Studies, Number 25, 143-148.

Givón, Talmy (1979): On Understanding Grammar. New York: Academic Press.

Glover, Ian/Bellwood, Peter (eds.) (2004): Southeast Asia. From Prehistory to History. London/ New York: RoutledgeCurzon.

Heine, Bernd/Kuteva, Tania (2008): "Constraints on contact-induced linguistic change”. Journal of Language Contact - THEMA 2: 57-90.

Heine, Bernd/Song, Kyung-An (2010): "On the genesis of personal pronouns: Some conceptual sources”. Language and Cognition 2.1: 117-148.

Heine, Bernd/Song, Kyung-An (2011): "On the grammaticalization of personal pronouns". Journal of Linguistics 47.3: 587-630.

Helmbrecht, Johannes (2013): "Politeness Distinctions in Pronouns". In: The World Atlas of Language Structures Online. Edited by Matthew S. Dryer and Martin Haspelmath. Leipzig: Max Planck Institute for Evolutionary Anthropology. (Available online at http://wals.info/ chapter/45, accessed on April 12, 2016).

Hinds, John (1986): Japanese. London/New York: Routledge.

Hopper, Paul J./Closs Traugott, Elizabeth (2003): Grammaticalization, second edition.

Cambridge: Cambridge University Press.

Huffman, Steve (2011): WorldGeoDatasets: Languages of Southeast Asia. Colorado Springs, CO: Global Mapping International. (Available online at http://www.worldgeodatasets.com, accessed on April 25, 2016).

Humboldt, Wilhelm von (1830): Über die Verwandtschaft der Ortsadverbien mit den Pronomen in einigen Sprachen. Berlin: Königliche Akademie der Wissenschaften.

Jenny, Mathias (2005): The Verb System of Mon. Zurich: ASAS.

Jenny, Mathias (2015): “Modern Mon”. In: The Handbook of Austroasiatic Languages. Edited by Mathias Jenny and Paul Sidwell. Leiden/Boston: Brill, 553-600.

Jenny, Mathias/McCormick, Patrick (2015): “Old Mon”. In: The Handbook of Austroasiatic Languages. Edited by Mathias Jenny and Paul Sidwell. Leiden/Boston: Brill, 519-552. 
Jenny, Mathias/Hnin Tun, San San (2016): Burmese: A Comprehensive Grammar. London/ New York: Routledge.

Kay, Paul (1976): “Discussion of papers by Kiparsky and Wescott”. In: Origin and Evolution of Language and Speech. Edited by Stevan R. Harnad, Horst D. Steklis and Jane Lancaster. New York, NY: New York Academy of Sciences, 17-19.

Keenan, Edward L. (1976): “Discussion”. In: Origin and Evolution of Language and Speech. Edited by Stevan R. Harnad, Horst D. Steklis and Jane Lancaster. New York, NY: New York Academy of Sciences, 92-96.

Kurokawa, Shozo (1972): "Japanese Terms of Address: some usages of the first and second person pronouns". Papers in Japanese Linguistics 1.2: 228-238.

Lee, Iksop/Ramsey, S. Robert (2000): The Korean Language. Albany, NY: State University of New York Press.

Lewis, M./Paul, Simons/Gary F./Fennig, Charles D. (eds.) (2016): Ethnologue: Languages of the World, Nineteenth edition. Dallas, TX: SIL International. (Available online at http://www. ethnologue.com, accessed on April 18, 2016).

Moeng, Sao Tern (1995): Shan-English Dictionary. Kensington: Dunwoody Press.

Noguchi, Tohru (1997): “Two types of pronouns and variable binding”. Language 73.4: 770-797.

Ohno, Toru (2005): “The structure of Pagán period Burmese”. In: Studies in Burmese Linguistics. Edited by Justin Watkins. Canberra: Pacific Linguistics, 241-305.

Panagiotidis, Phoevos (2002): “Pronominal Nouns”. In: Pronouns - Grammar and Representation. Edited by Horst J. Simon and Heike Wiese. Amsterdam/Philadelphia: John Benjamins Publishing Company, 183-203.

Pinnow, Heinz-Jürgen (1965): "Personal pronouns in the Austroasiatic languages: A historical study". Transl. by H. L. Shorto. Lingua 14: 3-42. Amsterdam: North-Holland Publishing Co.

Ricklefs, M. C./Lockhart, Bruce/Lau, Albert/Reyes, Portia/Aung-Thwin Maitrii (2010): A New History of Southeast Asia. Houndmills/New York: PALGRAVE MACMILLAN.

Schiering, René (2010): "Reconsidering erosion in grammaticalization: Evidence from cliticization". In: Grammaticalization: Current views and issues. Edited by Katerina Stathi, Elke Gehweiler and Ekkehard König. Amsterdam/Philadelphia: John Benjamins Publishing Company, 73-100.

Scott, James C. (2009): The Art of Not Being Governed. An Anarchist History of Upland Southeast Asia. New Haven/London: Yale University Press.

Sidwell, Paul (2015): The Palaungic Languages. Classification, Reconstruction and Comparative Lexicon. Munich: LINCOM GmbH.

Siewierska, Anna (2004): Person. Cambridge: Cambridge University Press.

Silverstein, Michael (1976): "Shifters, Linguistic Categories, and Cultural Description". In: Meaning in Anthropology. Edited by Keith H. Basso and Henry A. Selby. Albuquerque, NM: University of New Mexico Press, 11-55.

Silverstein, Michael (1988): Demeanor indexicals and honorific registers. Presented at Reed/ PSU Honorifics Conf., April 8-10.

Simon, Horst J./Wiese, Heike (eds.) (2002): Pronouns - Grammar and Representation. Amsterdam/Philadelphia: John Benjamins Publishing Company.

Strecker, David Shalom (1984): Proto-Tai personal pronouns. Unpublished dissertation: University of Michigan. 
Sugamoto, Nobuko (1989): “Pronominality: A Noun-Pronoun Continuum”. In: Linguistic Categorization. Edited by Roberta Corrigan, Fred Eckman and Michael Noonan. Amsterdam: John Benjamins, 267-291.

Tadmor, Uri (2015): “When culture grammaticalizes. The pronominal system of Onya Darat”. In: Language Structure and Environment. Social, Cultural, and Natural Factors. Edited by Rik de Busser and Randy J. LaPolla. Amsterdam/Philadelphia: John Benjamins Publishing Company, 77-98.

Thomason, Sarah G./Everett, Daniel L. (2001): "Pronoun borrowing”. Proceedings of the Berkeley Linguistic Society 27: 301-316.

Trudgill, Peter (2011): Sociolinguistic Typology: Social Determinants of Linguistic Complexity. Oxford: Oxford University Press.

Trudgill, Peter (2015): "Societies of intimates and linguistic complexity”. In: Language Structure and Environment. Social, Cultural, and Natural Factors. Edited by Rik de Busser and Randy J. LaPolla. Amsterdam/Philadelphia: John Benjamins Publishing Company, 133-147.

Yai Sein (2011): Ta Ang-English-Burmese (Rumai-English-Burmese) Dictionary. Nam Kham: Ta'ang Culture and Literature Committee. 